\title{
UMA PROPOSTA DE LEVANTAMENTO DE DADOS PARA AASSISTÊNCIA À FAMÍLIA E AO CUIDADOR DE LESADOS MEDULARES
}

\section{PROPOSAL OF BASIS SURVEY TO THE ASSISTANCE FAMILY AND TO THE SPINAL CORD INJURIED PATIENT'S CAREGIVER}

Ana Cristina Mancussi e Faro*

FARO, A.C.M.e. Uma proposta de levantamento de dados para a assistência à família e ao cuidador de lesados medulares. Rev. Esc. Enf. USP, v.33, n. 4, p. 334-41, dez. 1999

Este trabalho propõe um levantamento de dados para a assistência à familia e cuidador, por acreditar na necessidade de participação desta no tratamento, buscando compreender e compartilhar a situação de doença elou deficiência. Objetivouse identificar o grau de parentesco e o gênero das pessoas que acompanharam o lesado medular em consultas de enfermagem, bem como discutir a necessidade de levantamento de dados para a assistência à família e cuidador. Foram realizadas consultas de enfermagem, em ambulatorio, ao lesado medular e ao seu familiar, totalizando 36 pacientes. Deste total 26 eram do sexo masculino e 10 do sexo feminino. Constatou-se que os homens com lesão medular, na sua maioria (21) estavam acompanhados de parentes sobretudo mãe e esposa, enquanto que as mulheres com lesão medular, também a maioria (7) estavam acompanhadas de parentes de proximidade diversificada. No que se refere ao levantamento de dados, pode-se afirmar a sua relevância, buscando contextualizar o suporte familiar e identificar os cuidadores.

UNITERMOS: Família. Assistência de enfermagem.

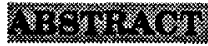

This study proposes a basis survey for assistance to the family and caregivers because we believe there is necessity of family participation on the treatment, trying to understand and share the disease or deficiency situation. We objectified to sketch the relationship degree and the people's gender that accompanied the spinal cord injuried hurted medular patient in nursing consultations and to discuss the necessity of basis survey to the assistance family and to the caregiver. 101 nursing consultations were accomplished, in clinic health, to the spinal cord injuried patient and his / her relative and 36 patients were totalized, from this number $26(72.22 \%)$ were male and 10 (27.78\%), were female. It was verified that the men with medular lesion, in the greater number (21-80.760/o), were accompanied with his relatives specially mother and wife, while the women with medular lesion, in the greater number too (7-70\%) were accompanied with her relatives of diversified proximity. ln reference to the basis survey that comprehend the care at house and the caregiver necessity, we can affirm its relevance, trying to context the family support identified attending the caregivers.

UNITERMS: Family. Nursing care.

\section{INTRODUÇÃO}

Fazendo uma retrospectiva da assistência e pesquisa por nós desenvolvidas durante a nossa vida profissional e acadêmica, especificamente na área de reabilitação do adulto com lesão medular, foi possivel identificar a necessidade crescente da assistência de enfermagem à família.

Um dos aspectos que nos leva a crer nesta demanda de assistência ainda é o espaço de tempo prolongado para que o lesado medular vincule-se a algum programa ou centro de reabilitação.

Podemos afirmar que esta espera faz com que o lesado medular seja atendido em ambulatórios gerais, muitas vezes não atrelados a centros de reabilitação, ficando ambos, paciente e família, com informações diversificadas sobre a situação instalada.

No doutoramento foi nossa preocupação estudar

\footnotetext{
- Professor Doutor do Departamento de Enfermagem Médico-Cirúrgica da Escola de Enfermagem da USP
} 
a trajetória do cuidar do lesado medular em reabilitação, quando nos propusemos validar intervenções de enfermagem. Neste estudo, constatamos que algumas dessas intervenções envolviam, também, a família.

Outros pesquisadores como COMARÚ et al (1978) desde então preocupadas em delinear a participação do enfermeiro num programa de reabilitação, preconizam que um grupo de profissionais de áreas específicas trabalhem direta e sistematicamente com o indivíduo.

Mesmo direcionando a assistência ao paciente, seja no atendimento ambulatorial ou na unidade de internação, é preciso conhecer o contexto familiar que o envolve. É evidenciar sua família, crenças, valores e aspectos relacionais de modo a destacar e ampliar o cuidar do adulto.

Ao enfermeiro cabe ler a mensagem explicitada por atos e atitudes do paciente como resposta deste à doença e/ou deficiência podendo estas respostas pessoais concorrerem para a alteração da dinâmica familiar, interferência no desempenho de papéis, conflitos e insegurança.

Por outro lado, o enfermeiro também traz consigo a sua referência de família, de crenças e valores sobre família, cuidar em casa, e principalmente sobre o impacto de doença, deficiência ou incapacidade na organização familiar.

Desta forma, seja no ambulatório, unidade de internação, centros de reabilitação, precisamos compreender que o impacto da doença e/ou deficiência, influenciam tanto o paciente como a família por toda vida, sendo necessário rever valores, crenças na busca de estratégias e habilidades potenciais que possam ser incorporadas a esta "nova situação" temporária ou definitiva, a qual terá que ser vivenciada. Ao enfermeiro cabe a parcela de compartilhar esta busca.

STASS Jr. et al (1992) pontuando o ajustamento individual e familiar comentam sobre o conceito incorreto de que há um "segundo momento no tempo", quando o paciente "aceita" ou "ajusta-se" à deficiência um processo para toda vida.

Acreditamos ser importante identificar a unidade familiar ou o sistema de suporte mais amplo do paciente. As repercussões da doença/deficiência na família não são somente emocionais, mas também muitas vezes físicos e econômicos. Os papéis assumidos pelo então "paciente" devem ser temporária ou definitivamente assumidos por outros familiares (STASS Jr. et al, 1992).

Cabe ainda aos familiares outras responsabilidades como o "cuidar do paciente" em casa, além das demais atividades diárias que vinham se desenvolvendo. A perda de controle sobre si mesmo, bem como sobre as situações antes rotineiras e o sentimento de desamparo se estendem a um complexo biopsicossocial, refletindo também na família.
KOVÁCS (1997) ao discutir a deficiência adquirida e qualidade de vida, considera a família como um organismo, na fase aguda. Há uma revolução e mudanças específicas que envolvem toda a família. É preciso lidar com o medo, a incerteza e o sofrimento. Continua esta autora que uma nova organização é necessária nas formas mais diversas, podendo ocorrer desorganização, ruptura ou reorganização, reunião e fortalecimento, não podendo se afirmar que há um padrão familiar.

Trata-se de respostas da família à situação de deficiência, processando a seu tempo, a escolha do cuidador ou a revelação desta pessoa, no interior da família.

KARSCH (1998) afirma que a figura do cuidador emerge numa relação intrínseca, ou seja, o cuidador só se expressa por intermédio da figura do paciente.

É um binômio indissolúvel que aparece como foco da ação do enfermeiro conforme apontado por COSTA; FARO (1997), FARO (1999), INOCENTINI; FARO (1998) e MANCUSSI (1998).

Quanto à expressão cuidador familiar, refere-se a uma pessoa da família ou alguém com fortes laços afetivos que dispensa atenção à pessoa doente ou deficiente em casa. Comumente, o cuidador familiar é oriundo da família, também denominado de cuidador informal, ou seja, sem formação na área de saúde (KARSCH, 1998)

Os papéis ou as responsabilidades assumidas anteriormente à doença ou trauma serão retomados temporária e definitivamente por um ou mais familiares. Assim, na reabilitação do lesado medular, os cuidados físicos serão os primeiros a ser aprendidos e os de ajustamento serão um contínuo por toda a vida (FARO, 1996).

A família deve ser participante do tratamento, recebendo suporte não apenas para aprender a cuidar do paciente, mas sobretudo subsídios para enfrentar, compreender e compartilhar a situação de doença e/ou deficiência, ajudando-a a lidar com seus próprios problemas, conflitos, medo e aumento de responsabilidades.

Desta maneira pretendemos, neste trabalho, mostrar o grau de parentesco e gênero das pessoas que acompanharam o lesado medular em consultas de enfermagem, sugerir e discutir a necessidade de levantamento de dados para a assistência à família e ao cuidador.

\section{Mãe, esposa, namorada ou prima ... quem é o cuidador?}

Durante 20 meses, compreendendo o período de janeiro de 1995 até setembro de 1996, em duas manhãs por mês, realizamos consultas de enfermagem ao lesado medular juntamente com seu familiar, no ambulatório de um hospital governamental. 
No referido serviço foram atendidas pelas autoras um total de 36 pessoas com lesão medular, sendo 26 homens e 10 mulheres.

Dos 26 pacientes do sexo masculino, observamos que 21 deles compareceram às consultas de enfermagem acompanhados de um cuidador familiar e os outros 5 pacientes vinham às consultas sozinhos.

Ainda com relação aos pacientes do sexo masculino (21), realizamos 101 consultas de enfermagem ao binômio paciente-familiar, compreendendo média de 4,8 consultas por paciente-familiar.

Acreditamos que os dados apresentados na forma de tabela ou de maneira descritiva possam facilitar a leitura e expressar melhor a realidade por nós vivida. Assim, mostraremos a seguir a descrição, por paciente, dos familiares atendidos, bem como o número de consultas para cada um deles.

Tabela 1- Distribuição de lesados medulares do sexo masculino e de seu(s) respectivo(s) cuidador(es) familiar(es) atendidos em consulta de enfermagem. São Paulo, 1998.

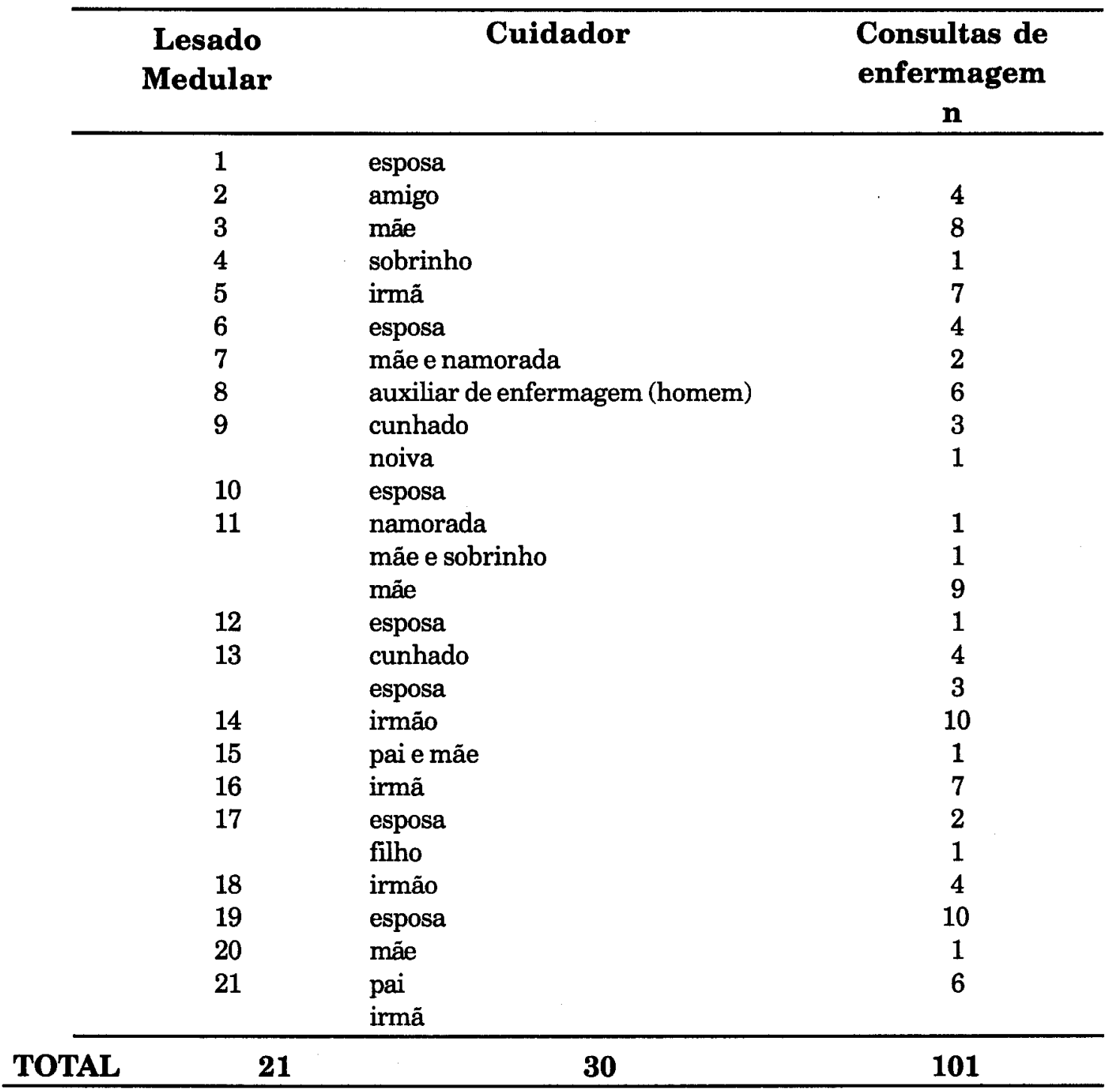

Diante destes resultados podemos constatar que a maioria dos familiares ou pessoas que se apresentaram como cuidadores de homens com lesão medular, são mulheres, predominantemente esposa e mãe. Ainda constatamos que 7 pacientes estavam acompanhados de mais de um familiar, havendo pelo menos um deles do sexo feminino.
Quanto às mulheres com lesão medular atendidas no mesmo período, totalizaram 10 pacientes, sendo que 7 delas compareceram às consultas de enfermagem acompanhadas de familiares, distribuídos como segue. 
Tabela 2 - Distribuição de lesados medulares do sexo feminino e de seu(s) respectivo(s) cuidador(es) familiar(es) atendidos em consulta de enfermagem. São Paulo, 1998.

\begin{tabular}{|c|c|c|}
\hline Lesado Medular & Cuidador & $\begin{array}{c}\text { Consultas } \\
\text { de enfermagem } \\
\mathbf{n}\end{array}$ \\
\hline 1 & mãe & 4 \\
\hline 2 & tia e irmã & 3 \\
\hline 3 & irmã & 1 \\
\hline 4 & ajudante (mulher) & 1 \\
\hline 5 & prima & 1 \\
\hline 6 & esposo & 1 \\
\hline 7 & filho & 1 \\
\hline TOTAL & 8 & 12 \\
\hline
\end{tabular}

Do total de mulheres com lesão medular (10), verificamos que 3 delas compareceram sozinhas às consultas.

Foram feitas 12 consultas de enfermagem a 7 pacientes e seu respectivo cuidador familiar, em média 1,7 consultas por paciente.

Podemos observar na tabela 2 a predominância de mulheres parentes ou não que acompanhavam outras mulheres. São de proximidade diversificada, (tia, prima, irmã e mãe). Apenas 2 homens (esposo e filho) apresentaram-se junto da paciente à consulta e, uma paciente esteve acompanhada nas consultas por dois familiares, ambos do sexo feminino.

PILSECKER (1990) fazendo um acompan-hamento de seis meses após alta hospitalar de uma população de 31 lesados medulares, constatou que 9 deles tinham como cuidadores suas esposas ou outro familiar não especificado, 5 outros pacientes referiram ter como cuidadores outras pessoas e 17 pacientes referiram ser auto-suficientes.

KILLEN (1990) estudando a estruturação familiar de lesados medulares verificou que o familiar mais próximo destes pacientes e que prestavam cuidados, eram as esposas; outros parentes também estavam participando do cuidado mas não predominavam.

Um relato de caso publicado por LAPHAMRANDLOV (1994), mostra o forte impacto sofrido por uma enfermeira de reabilitação enfrentando a lesão medular do marido. Segundo esta autora, inicialmente buscaram compreender porque esta tragédia teria acontecido nesta familia e, ainda, ela priorizou ser a esposa, não conseguindo atuar como "a enfermeira de reabilitação".

Este relato de caso vem nos mostrar o impacto sofrido pela família, e enquanto resposta desta o questionamento de suas vidas, expressando seus medos, suas dúvidas, buscando ajuda.

Realizamos um estudo no qual procuramos identificar a percepção das esposas de lesados medulares quanto à causa da internação e conhecer a fonte de informação sobre a condição clínica do paciente, bem como as necessidades destas esposas (FARO, 1992). Assim, nos foi possível observar que a maioria soube referir a causa da internação, mas associadas ao diagnóstico médico, ou seja, referiam fratura de coluna ou lesão medular sem se aterem às conseqüências destes eventos, sendo o médico, a enfermeira e o próprio paciente os informantes. Quanto às preocupações verbalizadas pelas esposas entrevistadas, podemos apontar as responsabilidades assumidas por ausência do marido; preocupação quanto ao próprio trabalho o que dificulta cuidar do marido; preocupação em como preparar o marido para encarar os fatos; dependência futura do marido.

A tese de doutoramento propiciou o repensar do processo de cuidar da família, visto que os diagnósticos de enfermagem elaborados, aos lesados medulares, a partir dos registros das enfermeiras no histórico de enfermagem, apontaram intervenções de enfermagem direcionadas à família ou ao binômio paciente-família. Estas intervenções tinham conteúdo voltado ao cuidado físico do lesado medular e à participação da família no treinamento do paciente ou mesmo no seu próprio treinamento e orientação para cuidar (FARO, 1995).

TOMÁS LLARAS (1997) consideram que o nível sócio-econômico médio-baixo interfere no sentido de que muitas pessoas dependem de um cuidador que, habitualmente, pertence à mesma familia. Estes cuidadores passam por situações angustiantes, agravadas quando não contam com suporte de profissionais ou mesmo por desconhecimento de cuidados específicos. Estes autores concluíram que os cuidadores sentiram-se satisfeitos por participarem do planejamento de cuidados e, também, por terem aprendido cuidados, sobretudo os que envolvem a mobilização e posicionamento do paciente seja na cama ou em cadeira de rodas.

Os resultados aqui descritos, mostram a organização ou a reorganização familiar, buscando reconstruir ou talvez reencontrar a unidade familiar abalada. 
PENNA (1992) em seu estudo afirma que a família é dinâmica e que existe enquanto unidade através da percepção e convivência de seus membros, sem contudo ser a somatória dos indivíduos que a compõe.

Sendo o lesado medular homem ou mulher, o familiar que o tem acompanhado no processo de reabilitação é, na maioria das vezes, uma mulher.

Disto podemos depreender que à mulher é atribuído o papel de cuidadora ou, minimamente, é aquela que tem potencial para cuidar. Embora tenhamos esboçado apenas o grau de parentesco e gênero do familiar, é oportuno lembrar que possivelmente algumas mulheres se dispõem a cuidar ou acompanhar o tratamento mais de perto pelos mais diferentes motivos. Ainda, vale ressaltar, a necessidade de outros estudos que possam evidenciar o perfil do cuidador, seus sentimentos e necessidades.

Amigos, parentes, composição familiar e cuidador... propondo um levantamento de dados para assistência à família.

A nossa prática de assistência ao lesado medular em ambulatório, permite-nos afirmar que as consultas de enfermagem implementadas são voltadas principalmente ao paciente e/ou família sempre que necessário.

Ao familiar e ao paciente temos orientado cuidados físicos como higiene corporal, conforto no leito e em cadeira de rodas, cateterismo vesical intermitente, mudança de decúbito, reeducação intestinal, prevenção de úlcera de pressão, cuidados no vestir/despir, curativos, orientações quanto à disfunção sexual, alimentação e hidratação.

Cabe ressaltar que mesmo o paciente apresentando condições funcionais para o seu autocuidado, o familiar deve participar das consultas de enfermagem, do aprendizado do paciente e interferindo neste plano de cuidados por meio da verbalização de suas dúvidas ou preocupações, além de propor adequações na organização do cuidar, como por exemplo, nos horários de cateterismo vesical, das evacuações, sono e repouso, contextualizando estas ações no dia a dia da família.

Outras vezes agendávamos consulta somente com a familia ou um familiar à medida que estes nos solicitavam ou, quando consideravamos necessário o reforço de algum cuidado ou, também, de apoio e esclarecimentos.

Em se tratando de atender a família ou cuidador juntamente com o lesado medular no ambulatório, sentimos a necessidade de estruturarmos um levantamento de dados referente ao cuidador familiar.

Assim apresentamos questões (ANEXO I) que se referem ao cuidador e que permitem fortalecer um canal de comunicação entre a enfermeira e familiar/cuidador nas consultas de enfermagem, propiciando proximidade entre todos no tratamento e estabelecimento de confiança mútua.

A partir destes dados é possível organizar conjuntamente, os cuidados a serem realizados em casa, considerando as necessidades do paciente no âmbito de sua família.
PENNA (1992) ao elaborar a análise de um referencial teórico de enfermagem à família apresenta conceitos dos quais destacaremos o de família e de assistência à família.

Esta autora afirma que familia consiste de uma unidade dinâmica constituída por pessoas que se percebem como família, que convivem por determinado espaço de tempo, com uma estrutura e organização para atingir objetivos comuns, construindo uma história de vida. Os membros da família estão unidos por laços consangüíneos, de adoção, interesse e/ou afetividade. Tem identidade própria, possui e transmite crenças, valores e conhecimentos comuns influenciados por sua cultura e nível sócio-econômico. A família tem direitos e responsabilidades, vive em um determinado ambiente em interação com outras pessoas e famílias, em diversos níveis de aproximação. Considerando esta conceituação, PENNA (1992) descreve a assistência à família como sendo o desenvolvimento de atividades realizadas por técnicos de diferentes áreas, parentes e/ou amigos, outras famílias e a comunidade, quando há mobilização recursos individuais e coletivos, pedindo apoio para enfrentar crises, conflitos e contradições, interagindo dinamicamente buscando mudanças no processo de viver.

Pautada em outras pesquisas que envolvem o lesado medular, bem como na literatura, elaboramos esta proposta de levantamento de dados e até o momento em que escrevemos este artigo a mesma foi aplicada a poucos familiares, mas caminhando para uma implementação mais sistemática.

O instrumento foi denominado de Dados relativos ao suporte familiar, sendo a segunda parte de uma coleta de dados sobre o lesado medular. A primeira parte compreende questões referentes à manutenção da integridade da pele, reeducação vesical, intestinal e disfunção sexual.

Os dados relativos ao suporte familiar compõem-se de questões abertas, feitas pela enfermeira ao familiar e/ ou cuidador familiar. São questões que abordam a identificação e composição da família, a dinâmica familiar, bem como identificação e caracterização do(s) cuidador(es), das orientações recebidas pelo cuidador para os cuidados em casa, e também sobre os cuidados realizados em casa. Quanto aos sentimentos, emoções e convívio familiar, são aspectos relevantes que merecem um canal de comunicação aberto enfermeiro-família.

Quando apresentamos o conceito de assistência à família (PENNA, 1992) observamos que a autora comenta sobre o processo de viver descrevendo-o como um processo que tem início na concepção do ser humano até sua transcendência, desenvolvendo-se continuamente a partir de todos os eventos, acontecimentos, situações que descrevem sua história de vida, através de suas interações sociais. Envolve todas as relações existentes do ambiente e as mudanças que estas provocam no viver coletivamente.

Outra definição de família que nos conduz a um repensar e a reiterar a importância da assistência éo descrito 
por LUCKMANN; SORENSEN (1996) afirmando que a definição depende do contexto, da situação do indivíduo bem como de sua perspectiva pessoal e para evitar a tendência de assumir incorretamente que todas as famílias atuam como a família de referência de alguém, devemos reconhecer que existe diferença entre suas perspectivas, valores e crenças daqueles de seus clientes. A família pode ser compreendida como um sistema dinâmico de duas ou mais pessoas que estão envolvidas emocionalmente umas com as outras e vivem próximas.

Diante destas considerações reiteramos a necessidade de um levantamento de dados à família mais organizado $e$ que permita inserí-los no tratamento ou no processo de reabilitação.

Em se tratando de pessoas com afecções crônicas, deficientes, idosos, cada vez mais, sua "institucionalização" é ambulatorial, internações necessárias são rápidas e, assim, vêm ao hospital ou centro de reabilitação mais esporadicamente, permanecendo a maior parte do tempo em casa, junto de familiares ou amigos.

Sabemos que o cuidador é na maioria das vezes, uma pessoa oriunda da própria família, ou é um amigo, ou uma pessoa contratada para este fim. Este último, deve ter formação na área de saúde e é denominado de cuidador formal (KARSCH, 1998; FARO, 1999).

É preciso identificar e caracterizar o cuidador, no sentido de melhor assisti-lo bem como a família, lembrando dos direitos, responsabilidades, valores da família, do cuidador e do paciente. Enfim, de suas histórias de vida, agora vivenciando a situação de alguém que, temporária ou definitivamente, não está podendo desempenhar seu papel antes definido ou esperado naquele contexto familiar.

MENDES (1998) afirma que a identidade do cuidador vai sendo construída no processo de cuidar do outro. É no seu fazer que a dimensão de cuidar vai sendo internalizada e concretizada. É no processo relacional com o outro (paciente) e consigo mesmo, que o cuidador vai produzindo para além da atividade de cuidar, a sua identidade.

Deste modo esperamos estar contribuindo com o desenvolvimento da profissão por acreditarmos que seja fundamental a leitura por parte do enfermeiro, da dinâmica familiar, bem como da identificação de cuidadores concomitante ao levantamento de dados sobre o paciente, possibilitando estruturar a assistência à pessoa e à família e não centrada nos limites da deficiência ou da doença, ampliando o núcleo da assistência e entendendo o binômio paciente/ cuidador como os componentes deste núcleo.

\section{REFERÊNCIAS BIBLIOGRÁFICAS}

COMARÚ M.N. et al. Participação do enfermeiro num Programa de Reabilitação - relato de experiência. Rev.Bras.Enf., v.31, n. 2, p.237-42, 1978.
COSTA, G.V.; FARO, A.C.M., e. Caracterização do cuidador familiar do lesado medular. São Paulo, 1997./mimeografado/.

FARO A.C.M. e. Percepção das esposas de pacientes portadores de lesão traumática da medula espinhal sobre a lesão medular. Rev. Saúde Dist.Fed., v.3, n.3/4, p.77-82, 1992.

FARO, A C.M. e. Do diagnóstico à conduta de enfermagem: a trajetória do cuidar na reabilitação do lesado medular. São Paulo, 1995. 207p. Tese (Doutoramento), Escola de Enfermagem, Universidade de São Paulo.

FARO, A.C.M.e. Assistência de enfermagem ao paciente com trauma raquimedular. In: VENTURA, M.F.; FARO, A.C.M. e; ONOE, E.K.N., UTIMURA, M. Enfermagem ortopédica. São Paulo, Ícone, 1996. p. 175-89

FARO, A.C.M. e. Cuidar do lesado medular em casa: a vivência singular do cuidador familiar. São Paulo, 1999. 127p. Tese (Livre Docência), Escola de Enfermagem, Universidade de São Paulo.

INOCENTINI, E.C.; FARO, A.C.M. e. O cuidar no âmbito familiar: percepções do binômio cuidador-paciente. São Paulo, 1998./mimeografado/.

KARSCH, U.M.S. A questão dos cuidadores. In: CONGRESSO PAULISTA DE GERIATRIA E GERONTOLOGIA, 1, São Paulo, 1998, Anais. São Paulo, 1998. p.28-31.

KILLEN, J.M. Role stabilization in families after spinal cord injury. Rehabil.Nurs., v.15, n.1, n.19-21, 1990.

KOVÁCS, M.J. Deficiência adquirida e qualidade de vida possibilidades de intervenção psicológica. In: MASINI E.A.F.S. et al. Deficiência: alternativas de intervenção. São Paulo, Casa do Psicólogo, 1997. p.95-125.

LAPHAN - RONDLOV, N. How the family copes with spinal cord injury: a personal perspective. Rehabil. Nurs., v.19, n.2, p.80-3, 1994.

LUCKMANN, M.; SORENSEM, L. Enfermagem médicocirúrgica, uma abordagem psico-fisiológica. Rio de Janeiro, Guanabara Koogan, 1996. cap.8, p.103-16: A família.

MANCUSSI, A.C. Assistência ao binômio paciente-família na situação de lesão traumática da medula espinhal. Rev.Lat.Am.Enf., v.6, n.4, p.67-73, 1998.

MENDES, P.M.T. Cuidadores: heróis anônimos do cotidiano. In: KARSCH, U.M.S. Envelhecimento com dependências: revelando cuidadores. São Paulo, Educ, 1998. cap.5, p.171-97.

PENNA, C.M. de M. Repensando o pensar: anlise crítica de um referencial teórico de enfermagem à família. Florianópolis, 1992.100p. Dissertação (Mestrado), Centro de Ciências da Saúde, Universidade Federal de Santa Catarina.

PILSECKER, C. Starting out: the first six months posthospital for spinal cord injuried veterans. Am.J.Phys.Med.Rehabil. v.69, n. 2, p. 91-5, 1990.

STASS Jr., W.E. et al. Reabilitação do paciente com traumatismo raquimedular. In: DELISA, J.A. Medicina de reabilitação: princípios e prática. São Paulo, Manole, v.2, p.735-62, 1992.

TOMÁS, A.T.; LLARAS, A.R. Cuidemos a los cuidadores. Rev.ROL Enf., n.222, p.13-5, 1997. 


\section{ANEXO I}

Parte II: Dados relativos ao suporte familiar

1. Nome do familiar:

idade: sexo:

2. Escolaridade:

3. Profissão/ ocupação:

4. Composição familiar:

5. Com quem o paciente mora?

6. O cuidador mora junto com o paciente?

7. Alguém trabalha fora de casa?

8. Há participação de outra(s) pessoa(s) para os cuidados realizados em casa? Quem é (são) esta(s) pessoa(s) e o que faz(em)?

9. Quais os cuidados realizados em casa atualmente?

10. Como são realizados estes cuidados (fazer, supervisionar, orientar, auxiliar)

11. A pessoa que cuida do paciente recebeu alguma orientação/treinamento para isso?

( ) Sim, qual e de quem?

( ) Sim, mas foi outro cuidador

( ) não 
12. Quanto tempo do dia você dispensa sua atenção ao paciente?

13. Há rodízio de familiares para a prestação de cuidados?

14. Você já cuidou de outro familiar?

( ) Sim, quanto tempo? quem era o familiar?

( ) Não

15. Atualmente, como você descreve o convívio familiar.

16. Você considera que houve mudanças neste convívio? Quais seriam?

17, Você gostaria de falar sobre como se sente?

18. O que você espera de nossa assistência para:

você

família

paciente 